\title{
Flow Cytometric Analysis of Cytologic Specimens in Hematologic Disease
}

\author{
Curtis A. Hanson and Bertram Schnitzer \\ Department of Pathology, University of Michigan Medical School, \\ Ann Arbor, Michigan
}

\begin{abstract}
Cytologic evaluation of body fluids and fine needle aspirations (FNA) is frequently required in patients with hematologic diseases. In this study we have correlated immunophenotyping and DNA analysis by flow cytometry with cytologic findings and tissue biopsies from 20 patients with body fluid specimens and 5 with FNA. Nineteen of 25 cases, including all FNA cases, had an immunophenotype consistent with malignancy: 12 monoclonal B-cell lymphomas, 2 T-cell lymphomas, 2 T-ALL and 3 non-T-ALL. By cytologic examination, 14 of
\end{abstract}

these 19 cases were positive for malignant cells, 2 suspicious and 3 negative; the latter 5 cases, including 2 FNA cases, had small monoclonal B-cell populations detected by flow cytometry. Six cases had a benign immunophenotype; cytologic examination was benign in 4 of these and suspicious for lymphoma in 2 . Our results show the feasibility of using flow cytometry to evaluate body fluids or FNA and demonstrate that small malignant populations that may be missed by routine cytology can be detected by flow cytometry.

Key words: flow cytometry, cytology, leukemia, lymphoma

\section{INTRODUCTION}

The cytologic evaluation of body fluids, including cerebrospinal (CSF), pleural, and ascitic fluids from patients with leukemia or lymphoma, is frequently required to assess the spread or stage of disease (1). Fine needle aspiration (FNA) of lymph nodes is also becoming a frequent diagnostic procedure in the evaluation of patients suspected of having a possible lymphoproliferative disorder (2). In most instances, cytologic evaluation for malignant cells in Wrightand/or Papanicolaou-stained smears or cytocentrifuge preparations is sufficient.

However, not all cytology specimens of suspected lymphoreticular neoplasms can be diagnosed with certainty, especially if the cells lack characteristic morphologic features of malignancy. For example, differentiation of benign lymphocytes from cells of acute lymphoblastic leukemia of the FAB-L1 type in the CSF may not be possible (1). Similarly, the distinction of small cell lymphomas, small cleaved cell lymphomas, or peripheral T-cell lymphomas from normal lymphocytes in CSF or pleural fluid can be extremely difficult on morphologic grounds alone. These same problems also apply to the interpretation of FNA of suspected lymphoid neoplasms (2).

Flow cytometric analysis has become the standard method of immunophenotyping bloods and bone marrows of patients with leukemia or lymphoma and is easily adapted to the evaluation of body fluids and lymph node aspirates (3-8). Detection of a leukemic immunophenotype, monoclonal surface immunoglobulin (sIg), or an aberrant immunophenotype in a cytologic specimen would confirm the presence of leukemia or lymphoma. Also, small populations of malignant cells that may be missed by routine morphology can be detected by flow cytometry $(9,10)$. DNA analysis by flow cytometry for the determination of ploidy or the cell cycle percentage can also be used to detect malignant cells (4$8,11-21)$. The presence of an aneuploid population would strongly suggest a malignant process, whereas a high percentage of cells in the S-G2-M proliferative phase of the cell cycle in a cytologically lymphomatous proliferation can be used to grade the lymphoma according to the working formulation of non-Hodgkin's lymphomas $(22,23)$.

The purpose of this study was to utilize all these capabilities of flow cytometry to detect leukemia or lymphoma cells in the analysis of body fluids and FNA specimens. The flow cytometric data obtained were compared to the cytologic interpretation along with the tissue biopsy diagnosis to determine the practical feasibility of using flow cytometry to evaluate body fluids and FNA.

Received May 5, 1988; accepted July 29, 1988.

Address reprint requests to Dr. Curtis A. Hanson, Department of Pathology, University of Michigan Medical School, M5242 Medical Science I, Ann Arbor, Ml 48109-00602.

Presented in part before the International Academy of Pathology, Washington, D.C., February 28-March 3, 1988 (Lab Invest 1988; 58:37A). 
TABLE 1. Monoclonal Antibodies and Lymphoid Reactivity

\begin{tabular}{|c|c|c|}
\hline $\begin{array}{l}\text { Monoclonal } \\
\text { antibody }\end{array}$ & $\begin{array}{c}\text { Cluster } \\
\text { designation }\end{array}$ & Cellular reactivity \\
\hline T6 & CD1 & Common thymocyte \\
\hline T11 & $\mathrm{CD} 2$ & Pan-T-cell, pan-thymocyte \\
\hline T3 & CD3 & Mature T-cell, medullary thymocyte \\
\hline T4 & CD4 & Helper/inducer mature T-cell, medullary thymocyte \\
\hline Leul & CD5 & Pan-T-cell, pan-thymocyte, chronic lymphocytic leukemia \\
\hline Leu9 & CD7 & Pan-T-cell, pan-thymocyte, some myeloid cell \\
\hline T8 & $\mathrm{CD} 8$ & Suppressor/cytotoxic mature T-cell, medullary thymocyte \\
\hline $\mathrm{J} 5$ & CD10 & $\begin{array}{l}\text { CALLA, non-T-cell acute lymphocytic leukemia, nodular } \\
\text { lymphoma }\end{array}$ \\
\hline B4 & CD19 & Pan-B-cell \\
\hline B 1 & CD20 & Intermediate mature B-cell \\
\hline B2 & CD21 & Intermediate B-cell \\
\hline $\operatorname{IgG}$ & - & $\gamma$ Heavy chain \\
\hline $\operatorname{IgA}$ & - & $\alpha$ Heavy chain \\
\hline $\lg M$ & - & $\mu$ Heavy chain \\
\hline IgD & 一 & $\delta$ Heavy chain \\
\hline Kappa & - & Kappa light chain \\
\hline Lambda & - & Lambda light chain \\
\hline Mo1 & CD11b & Monocyte/granulocyte \\
\hline LeuM5 & CD1lc & Monocyte/hairy cell leukemia \\
\hline My7 & CD13 & Monocyte/immature myeloid cells \\
\hline My9 & CD34 & Monocyte/immature myeloid cells \\
\hline $\mathrm{I} 2$ & - & HLA-DR \\
\hline TdT & - & Hematopoietic stem cell, lymphoblast, some myeloblasts \\
\hline
\end{tabular}

TABLE 2. Tissue Biopsy Diagnosis and Cytologic Specimen

\begin{tabular}{|c|c|c|}
\hline Diagnosis & No. of cases & Cytology specimen \\
\hline Non-T-cell ALL & 3 & $\mathrm{CSF}^{\mathrm{a}}(2), \mathrm{PF}^{\mathrm{b}}$ \\
\hline T-cell ALL & 1 & CSF \\
\hline Burkitt's leukemia/lymphoma & 1 & PF \\
\hline Chronic lymphocytic leukemia & 1 & $\mathrm{PF}$ \\
\hline T-lymphoblastic lymphoma & 2 & PF, FNA ${ }^{\mathrm{c}}$ \\
\hline Peripheral T-cell lymphoma & 1 & CSF \\
\hline Cutaneous T-cell lymphoma (Sezary) & 1 & PF \\
\hline Follicular, small cleaved cell lymphoma & 8 & $\mathrm{CSF}, \mathrm{PF}(4), \mathrm{AF}^{\mathrm{d}}(2), \mathrm{FNA}$ \\
\hline Follicular, mixed lymphoma & 2 & PF, FNA \\
\hline Diffuse, large cell lymphoma & 1 & FNA \\
\hline Lymphoplasma-cytoid lymphoma (Waldenstrom's) & 2 & $\mathrm{PF}(2)$ \\
\hline Granulomas & 1 & PF \\
\hline Ewing's sarcoma & 1 & FNA \\
\hline
\end{tabular}

${ }^{a}$ Cerebrospinal fluid.

${ }^{b}$ Pleural fluid.

${ }^{c}$ Fine needle aspiration.

${ }^{\mathrm{d} A s c i t i c}$ fluid.

\section{MATERIALS AND METHODS}

Body fluids or FNA specimens were simultaneously obtained for both flow cytometric and cytologic analysis in 25 patients. Twenty body fluids were evaluated: 5 CSF, 13 pleural fluids, and 2 ascitic fluids. Five FNA were also stud- ied; 3 aspirates were obtained from enlarged lymph nodes and 2 from extranodal masses. Cytologic evaluation of the body fluid specimens and the FNA was performed on either Wright- and/or Papanicolaou-stained cytocentrifuge preparations. A tissue biopsy was available in all cases and was 
TABLE 3. Cytology and Immunophenotype: Both Cytology and Immunophenotype Positive for Malignancy

\begin{tabular}{|c|c|c|}
\hline $\begin{array}{l}\text { Tissue biopsy } \\
\text { diagnosis }\end{array}$ & $\begin{array}{l}\text { Cytology specimen/ } \\
\text { interpretation }\end{array}$ & Immunophenotype/interpretation \\
\hline Non-T-cell ALL & CSF/positive & DR, B4, CALLA/non-T-cell ALL \\
\hline Non-T-cell ALL & CSF/positive & DR, B4, CALLA/non-T-cell ALL \\
\hline Non-T-cell ALL & PF/positive & DR, B4, B1, CALLA/non-T-cell ALL \\
\hline T-cell ALL & CSF/positive & T11, T6, Leu9/T-cell ALL \\
\hline Burkitt's leukemia/lymphoma & $\mathrm{PF} /$ positive & IgM, kappa, B1/consistent with Burkitt's \\
\hline Chronic lymphocytic leukemia & $\mathrm{PF} /$ positive & IgD, IgM, lambda, Leu1/CLL \\
\hline T-lymphoblastic lymphoma & $\mathrm{PF} /$ positive & $\begin{array}{l}\text { T11, T6, Leu9, TDT/T-lymphoblastic } \\
\text { lymphoma }\end{array}$ \\
\hline T-lymphoblastic Iymphoma & FNA/positive & $\begin{array}{l}\text { T11, T6, Leu9, TDT/T-lymphoblastic } \\
\text { lymphoma }\end{array}$ \\
\hline Follicular, small cleaved cell lymphoma & PF/positive & IgD, IgM, kappa, B1/B-cell lymphoma \\
\hline Follicular, small cleaved cell lymphoma & $\mathrm{PF} /$ positive & IgD, IgM, kappa, B1/Leu1/B-cell lymphoma \\
\hline Follicular small cleaved cell lymphoma & AF/positive & IgM, lambda, B1/B-cell lymphoma \\
\hline Follicular, mixed lymphoma & $\mathrm{PF} /$ positive & kappa, B1/B-cell lymphoma \\
\hline Follicular, mixed lymphoma & FNA/positive & IgD, IgM, kappa, B1/B-cell lymphoma \\
\hline $\begin{array}{l}\text { Lymphoplasmacytoid lymphoma } \\
\text { (Waldenstrom's) }\end{array}$ & $\mathrm{PF} /$ positive & IgM, kappa, B1, B4/B-cell lymphoma \\
\hline
\end{tabular}

performed either prior or subsequent to the cytologic evaluation.

Flow cytometric studies of the body fluids and FNA included monoclonal antibody immunophenotyping in all cases and DNA analysis for ploidy and cell cycle analysis in 7 cases. Body fluids and FNA were sent to the laboratory either fresh or in cell culture media. The isolated cells were then processed through a Ficoll-Hypaque gradient with viability determined by trypan blue staining and a cell concentration obtained with a Coulter counter and channelyzer. The number of antibodies subsequently used depended upon the number of viable cells obtained from the separation procedure. The monoclonal antibodies utilized in this study are listed in Table 1; the antibodies chosen for analysis were based on whether the individual case was suspected to be a leukemia or lymphoma. An indirect immunofluorescence staining procedure was used. The cells were separated into subpopulations based on light scatter characteristics using an Epics V Flow Cytometer; 5,000 to 10,000 cells per marker were analyzed (24). The results obtained were then analyzed with a subtraction program (IMMUNO; Coulter Corporation) in which the percentage of cells positive for each marker from the patient sample was determined after subtraction of background and nonspecific labeling with a typespecific mouse monoclonal antibody.

DNA ploidy and cell cycle analyses were performed in 7 cases on cells isolated from the same samples used for immunophenotyping, as described above. The cell suspension was adjusted to a concentration of $1 \times 10^{7}$ and then nuclear DNA prepared using the Vindelov procedure (25). Briefly, cells were suspended in a solution containing propidium iodide (PI) to stain nucleic acids and RNAse to digest RNA. A nonionic detergent, NP-40, was added to lyse the cytoplasmic membrane and cytoplasm, leaving the nuclear envelope intact and permeable to PI (6). The DNA ploidy, or
DNA index, was determined by the relative position of the G0G1 peak of the cytologic specimen as compared to the G0G1 peak of normal control peripheral blood lymphocytes (6). Cell cycle analysis for the number of cells in the G1, S, and $\mathrm{G} 2+\mathrm{M}$ phases was performed by analyzing histograms using both parametric and nonparametric routines (EASY 1, PARA 1 and NONPAR; Coulter Corporation).

\section{RESULTS}

The tissue biopsy diagnosis, the cytologic diagnosis, and the source of the cytology specimen of the 25 cases are listed in Table 2. These included 5 cases of acute lymphocytic leukemia (ALL) and 1 of chronic lymphocytic leukemia. Seventeen of the remaining 19 cases had biopsy diagnoses of non-Hodgkin's lymphoma; tissue biopsies in the 2 other cases showed a lymph node with granulomas and a paraspinal mass with Ewing's sarcoma, respectively.

Cytologic evaluation showed that 14 of the specimens were positive for malignant cells (Table 3); all of the leukemic cases and 2 of the FNA specimens were interpreted as positive by cytologic examination. The 3 other FNA preparations and 1 pleural fluid preparation were cytologically suspicious for malignant cells (Table 4A). The cells in question were either too few in number to accurately assess the presence of malignancy, or else they were only slightly atypical in appearance as might be seen in a low grade lymphoma. The remaining 7 cases were cytologically negative for malignancy (Table 4B and 4C).

Flow cytometric immunophenotyping confirmed the cytologic diagnosis in 18 cases: the immunophenotype was positive for malignancy in 14 of these cases and negative in 4 (Table 3 and 4C). Three cases of acute leukemia were phenotyped as CALLA-positive non-T-cell ALL, one as T-cell ALL, and one as a monoclonal sIg positive Burkitt's leukemia/lymphoma. Two cases were T-cell lymphoblastic lym- 
TABLE 4. Cytology and Immunophenotype

\begin{tabular}{lcc}
$\begin{array}{l}\text { Tissue biopsy } \\
\text { diagnosis }\end{array}$ & $\begin{array}{c}\text { Cytology specimen/ } \\
\text { interpretation }\end{array}$ & $\begin{array}{c}\text { Immunophenotype/ } \\
\text { interpretation }\end{array}$ \\
\hline
\end{tabular}

A. Cytology Suspicious for Malignancy; Immunophenotype Positive or Negative for Malignancy

$\begin{array}{ll}\text { Follicular, small cleaved cell lymphoma } & \text { FNA/suspicious } \\ \text { Diffuse, large cell lymphoma } & \text { FNA/suspicious } \\ \text { Follicular, small cleaved cell lymphoma } & \text { PF/suspicious } \\ \text { Ewing's sarcoma } & \text { FNA/suspicious }\end{array}$

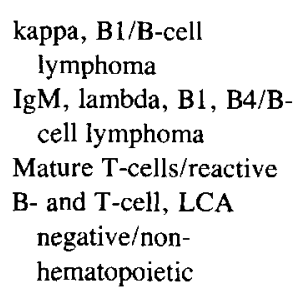

B. Cytology Negative for Malignancy; Immunophenotype Positive or Negative for Malignancy

$\begin{array}{ll}\text { Follicular, small cleaved cell lymphoma } & \text { AF/negative } \\ \begin{array}{ll}\text { Lymphoplasma-cytoid lymphoma } \\ \text { (Waldenstrom's) }\end{array} & \text { PF/negative } \\ \text { Peripheral T-cell lymphoma } & \text { CSF/negative }\end{array}$

IgD, IgM, kappa/B-cel! lymphoma

IgM, kappa, B1, B4/B-cell lymphoma

Peripheral T-cell lymphoma CSF/negative

T11, Leu9, T8 positive;

T3, T4 negative/ peripheral T-cell lymphoma

C. Both Cytology and Immunophenotype Negative for Malignancy

\begin{tabular}{lll} 
Follicular, small cleaved cell lymphoma & $\mathrm{PF} /$ negative & Mature T-cells/reactive \\
Follicular, small cleaved cell lymphoma & $\mathrm{PF} /$ negative & Mature T-cells/reactive \\
Cutaneous T-cell lymphoma (Sezary) & $\mathrm{PF} /$ negative & T11, Leu1, T8/reactive \\
Granulomas & PF/negative & Mature T-cells/reactive \\
\hline
\end{tabular}

phomas, and 7 had a monoclonal sIg consistent with B-cell lymphoma. The remaining 4 cases with both a benign cytology and immunophenotype consisted primarily of a population of mature T-cells with a normal to slightly increased CD4:CD8 ratio.

Of the four cases suspicious for lymphoreticular malignancy (Table 4A), 2 were found to have a population of cells with a monoclonal $\mathrm{sIg}$, consistent with a B-cell lymphoma; both of these cases were from FNA. In both of these instances, the malignant population comprised less than $20 \%$ of the lymphoid subpopulation by flow cytometry. The other 2 cases in which cytologic examination was suspicious for lymphoma were found to be benign by immunophenotyping; one, a pleural fluid from a case of follicular small cleaved cell lymphoma contained only mature T-cells, and the other, a FNA of a paraspinal mass was negative with all B-cell, Tcell, and anti-leukocyte common antigen monoclonal antibodies. Subsequent tissue biopsy of this latter case revealed a Ewing's sarcoma.

In the 3 remaining cases, a follicular small cleaved cell lymphoma, a lymphoplasmacytoid lymphoma, and a peripheral T-cell lymphoma, body fluids that had been interpreted as benign by cytologic examination had an immunophenotype positive for lymphoma (Table 4B). Two of these cases had small populations of cells with a monoclonal sIg, consistent with a B-cell lymphoma; the immunophenotype of the other case showed the CSF cells in question to be CD2, CD5, CD8 positive, and CD7, CD3, and CD4 negative. This aberrant $\mathrm{T}$-cell phenotype was also found in a lymph node biopsy specimen and was felt to be consistent with a peripheral T-cell lymphoma.

DNA ploidy determination and cell cycle analysis were performed in 7 cases, all with cytologies positive for malignant cells confirmed by immunophenotypic analysis. These included a T-cell lymphoblastic lymphoma (T-LL), a chronic lymphocytic leukemia, 4 B-cell non-Hodgkin's lymphomas, and a plasmacytoid lymphoma (Waldenstrom's macroglobulinemia). Five cases had a normal DNA index; a prominent hyperdiploid population was seen in a diffuse large cell lymphoma and a hypodiploid population in a Waldenstrom's macroglobulinemia, respectively. These latter 2 cases and the T-LL case showed greater than $20 \%$ of the cells to be in the S-G2-M phase of the cell cycle, indicating a high proliferative rate; the remaining 4 cases all showed normal cell cycle kinetics.

\section{DISCUSSION}

Nineteen of the 25 cases evaluated in this study by flow cytometric immunophenotyping had an immunophenotype consistent with malignancy: 3 non-T-cell, CALLA positive ALL, 2 T-cell ALL, 2 T-cell lymphomas and 12 monoclonal sIg positive lymphomas. Of these 19 cases, 14 were cytologically positive, 2 were suspicious, and 3 negative for malignant cells. Of the 6 cases with a benign immunophenotype, cytologic examination was benign in 4 and suspicious for lymphoma in 2 . 
The findings in this study confirm that flow cytometry can be used to immunophenotype body fluids and FNA in cases suspected of being involved by leukemia and lymphoma (3$8,11-21)$. Although cytologic examination is generally reliable in diagnosing body fluids and FNA, flow cytometry offers an objective technique to confirm or refute cytologic interpretation. In particular, it may be useful in the distinction of the small cells with relatively coarse chromatin seen in both ALL, FAB-L1, and normal lymphocytes. In addition, the relatively bland-appearing cells of the low grade lymphomas may be confused with benign reactive lymphocytes in cytologic specimens; the presence of a monoclonal sIg confirms the presence of a clonal B-cell proliferation consistent with lymphoma, as seen in 4 cases of this study. Cells of peripheral T-cell lymphomas (PTCL), which may appear as overtly atypical or malignant, may also have a bland appearance on cytocentrifuge preparations and be indistinguishable cytologically from benign lymphocytes. Comparison of cytologic features, morphologic appearance of the biopsy, and an aberrant immunophenotype characterized by loss of expression of one or more of the pan-T-cell antigens permits the diagnosis of PTCL in which clonality cannot be determined by immunophenotype (26).

The advantages of flow cytometry lie in its ability to evaluate objectively a large number of cells over a relatively short time period. Also, the ability of flow cytometry to focus on a group of cells based on cell size and light scatter characteristics allows for the analysis of discrete subpopulations of cells with particular light scatter characteristics (27). This permits the detection of small populations of malignant cells $(9,10)$. In all instances in this study in which cytology was either negative or suspicious for malignancy and in which positive flow cytometric findings were found, the cells with a malignant immunophenotype were present in subpopulations containing only a small percentage of the total cell number. This latter capability of flow cytometry is probably best applied to those specimens in which the cytologic interpretation is suspicious for malignant cells, but malignancy cannot be determined with certainty due to an insufficient number of cells with an atypical appearance.

The major limiting factor of using flow cytometry in the evaluation of body fluids and FNA is in obtaining sufficient cells for analysis with the battery of monoclonal antibodies desired. Cerebrospinal fluids in particular offer logistical problems for flow cytometric evaluation since only a limited volume of fluid and number of cells are usually available. In FNA, multiple needle passes may be necessary to obtain sufficient cells for both routine morphology and flow cytometric studies. In both of these instances, alternative methods for immunophenotyping such as immunofluorescence or immunoperoxidase staining of cytocentrifuge preparations should be considered (28).

The flow cytometric evaluation of certain types of high grade lymphomas can also present technical problems. The malignant cells of large cell or immunoblastic lymphomas often have poor viability after the separation steps used in immunophenotyping studies; this can lead to preservation of a predominant population of smaller nonmalignant cells and loss of the diagnostic large neoplastic cells. Thus the inadvertent misdiagnosis of benignity by flow cytometry may result when a malignant diagnosis is obvious by cytology. Morphologic examination of the separated cytocentrifuged cells used for immunophenotyping is necessary to ensure that the same cells seen in a cytologic specimen are being evaluated by flow cytometry.

Other studies have shown the utility of analyzing body fluids for DNA content in the evaluation of malignant diseases, including both solid tumor neoplasms and hematopoietic malignancies (3-8,11-21). Few reports, however, have demonstrated the use of immunophenotyping to characterize body fluid effusions in characterizing malignant lymphoma and acute leukemia (3-8). As our results showed, immunophenotyping may detect a malignant population of cells that is not recognized by DNA analysis.

In conclusion, flow cytometric evaluation of body fluids and FNA is easily accomplished and provides an additional and objective method for the detection of malignant cells in cytologic specimens.

\section{REFERENCES}

1. Borowitz M, Bigner SH, Johnston WW: Diagnostic problems in the cytologic evaluation of cerebrospinal fluid for lymphoma and leukemia. Acta Cytol 25:665-674, 1981.

2. Ramzy I, Rone R, Schultenover SJ, Buhaug J: Lymph node aspiration biopsy. Diagnostic reliability and limitations-an analysis of 350 cases. Diag Cytopathol 1:39-45, 1985.

3. Johnson A, Akerman M, Cavallin-Stahl E: Flow cytometric detection of B-clonal excess in fine needle aspirates for enhanced diagnostic accuracy in non-Hodgkin's lymphoma in aduits. Histopathol 11:581$590,1987$.

4. Redner A, Melamed MR, Andreef M: Detection of central nervous system relapse in acute leukemia by multiparameter flow cytometry of DNA, RNA, and CALLA. Ann NY Acad Sci 468:241-255, 1986.

5. Avent J: Flow cytometry in body fluid analysis. Clin Lab Med 5:389403, 1985.

6. Flint A, Lovett EJ, Stoolman LM, McMillan K, Schnitzer B, McClatchey KD, Hudson JL: Flow cytometry analysis of DNA in diagnostic cytology. Am J Clin Pathol 84:278-282, 1985.

7. Katz RL, Raval P, Manning JT, McLaughlin P, Barlogie B: A mor phologic, immunologic, and cytometric approach to the classification of non-Hodgkin's lymphoma in effusions. Diag Cytopathol 3:91-101, 1987.

8. O'Hara MF, Cousar JB, Glick AD, Collins RD: Multiparameter approach to the diagnosis of hematopoietic-lymphoid neoplasms in body fluids. Diag Cytopathol I:33-38, 1985.

9. Ryan DH, Mitchell SJ, Hennessy LA, Bauer KD, Horan PK, Cohen HJ: Improved detection of rare CALLA-positive cells in peripheral blood using multiparameter flow cytometry. I Immunol Methods 74:115-128, 1984.

10. Visser FWM, Martens ACM, Hagenbeek A: Detection of minimal residual disease in acute leukemia by flow cytometry. Ann NY Acad Sci 468:268-275, 1986.

11. Redner A, Andreef M, Miller DR, Stinherz P, Melamed M: Recognition of central nervous system leukemia by flow cytometry. Cytometry 5:614-618, 1984. 
12. Cibas ES, Malkin MG, Posner JB, Melamed MR: Detection of DNA abnormalities by flow cytometry in cells from cerebrospinal fluid. $A m$ $J$ Clin Pathol 88:570-577, 1987.

13. Stonesifer KJ, Xiang J, Wilkinson EJ, Benson NA, Braylan RC: Flow cytometric analysis and cytopathology of body cavity fluids. Acta Cytol 31:125-130, 1987.

14. Barwick KW: Flow cytometry. A new technique in the diagnosis of malignant ascites. J Clin Gastroenterol 9:599-602, 1987.

15. Unger KM, Raber M, Bedrossian CWM, Stein DA, Barlogie B: Analysis of pleural effusions using automated flow cytometry. Cancer 52:873-877, 1983.

16. Hedley DW, Philips J, Rugg CA, Taylor IW: Measurement of cellular DNA content as an adjunct to diagnostic cytology in malignant effusions. Eur J Cancer Clin Oncol 20:749-752, 1984.

17. Evans DA, Thornthwaite JT, Ng ABP, Sugarbaker EV: DNA flow cytometry of pleural effusions. Comparison with pathology for the diagnosis of malignancy. Analyt Quant Cytol 5:19-27, 1983.

18. Colvin RB, Preffer FI: New technologies in cell analysis by flow cytometry. Arch Pathol Lab Med 111:628-632, 1987.

19. Greenebaum E, Koss LG, Sherman AB, Elequin F: Comparison of needle aspiration and solid biopsy technics in the flow cytometric study of DNA distributions of surgically resected tumors. Am J Clin Pathol 82:559-564, 1984.

20. Holdrinet RSG, Pennings A, Srenthe-Schonk AM, Van Egmond J, Wessels JMC, Haanen C: Flow cytometric determination of the Sphase compartment in adult acute leukemia. Acta Haemat 10:369 378,1983
21. Schneller J, Eppich E, Greenebaum E, Elequin F, Sherman A, Wersto $R$, Koss LG: Flow cytometry and Feulgen cytophotometry in evaluation of effusions. Cancer 59:1307-1313, 1987.

22. Braylan RC, Benson NA, Nourse VA: Cellular DNA of human neoplastic B-cells measured by flow cytometry. Cancer Res 44:50105016, 1984.

23. Bauer KD, Merkel DE, Winter JN, Marder RJ, Hauck WW, Wallemark CB, Williams TJ, Variakojis D: Prognostic implications of ploidy and proliferative activity in diffuse large cell lymphomas. Cancer Res 46:3173-3178, 1986.

24. Slade HB, Greenwood JH, Hudson JL, Beekman RH, III, Riedy MC, Schwartz SA: Lymphocyte phenotyping of infants with congenital heart disease: Comparison of cell preparation techniques. Diag Clin Immunol 5:249-255, 1988.

25. Vindelov LL: Flow microfluorometric analysis of nuclear DNA in cells from solid tumors and cell suspensions. Virchows Arch B 24:227242, 1977.

26. Picker LJ, Weiss LM, Medeiros LJ, Wood GS, Warnke RA: Immunophenotypic criteria for the diagnosis of non-Hodgkin's lymphoma. Am J Pathol 128:181-201, 1987.

27. Lovett EJ, III, Schnitzer B, Keren DF, Flint A, Hudson JL, McClatchey KD: Application of flow cytometry to diagnostic pathology. Lab Invest 50:115-140, 1984.

28. Martin SE, Zhang H-Z, Magyarosy E, Jaffe ES, Hsu S-M, Chu EW: Immunologic methods in cytology: definitive diagnosis of non-Hodgkin's lymphomas using immunologic markers for T- and B-cells. Am J Clin Pathol 82:666-673, 1984. 